Elsevier required licence: (c) $<2018>$. This manuscript version is made available under the CC-BY-NC-ND 4.0 license http://creativecommons.org/licenses/bync-nd/4.0/ 


\title{
Performance, microbial community and fluorescent characteristic of microbial products in a solid-phase denitrification biofilm reactor for WWTP effluent treatment
}

\author{
Fei Han ${ }^{\mathrm{a}}$, Dong $\mathrm{Wei}^{\mathrm{a}}$, Huu Hao Ngo ${ }^{\mathrm{b}}$, Wenshan Guo ${ }^{\mathrm{b}}$, Weiying $\mathrm{Xu}^{\mathrm{a}}$, Bin $\mathrm{Du}^{\mathrm{a}, *}$, Qin Wei ${ }^{\mathrm{c}}$ \\ ${ }^{a}$ School of Resources and Environment, University of Jinan, Jinan 250022, PR China \\ ${ }^{\mathrm{b}}$ School of Civil and Environmental Engineering, University of Technology Sydney, Broadway, NSW 2007, Australia \\ ${ }^{c}$ Key Laboratory of Chemical Sensing \& Analysis in Universities of Shandong, School of Chemistry and Chemical Engineering, University of Jinan, Jinan 250022, PR China
}

\section{A R T I C L E I N F O}

\section{Keywords:}

Denitrification

Extracellular polymeric substance

Microbial products

Parallel factor analysis

Gas chromatography-mass spectrometer (GCMS)

\begin{abstract}
A B S T R A C T
Microbial products, i.e. extracellular polymeric substance (EPS) and soluble microbial product (SMP), have a significant correlation with microbial activity of biologically based systems. In present study, the spectral characteristics of two kinds of microbial products were comprehensively evaluated in a solid-phase denitrification biofilm reactor for WWTP effluent treatment by using poly (butylene succinate) (PBS) as carbon source. After the achievement of PBS-biofilm, nitrate and total nitrogen removal efficiencies were high of $97.39 \pm 1.24 \%$ and $96.38 \pm 1.1 \%$, respectively. The contents of protein and polysaccharide were changed different degrees in both LB-EPS and TB-EPS. Excitation-emission matrix (EEM) implied that protein-like substances played a significant role in the formation of PBS-biofilm. High-throughput sequencing result implied that the proportion of denitrifying bacteria, including Simplicispira, Dechloromonas, Diaphorobacter, Desulfovibrio, increased to $9.2 \%, 7.4 \%, 4.8 \%$ and $3.6 \%$ in PBS-biofilm system, respectively. According to EEM-PARAFAC, two components were identified from SMP samples, including protein-like substances for component 1 and humiclike and fulvic acid-like substances for component 2, respectively. Moreover, the fluorescent scores of two components expressed significant different trends to reaction time. Gas chromatography-mass spectrometer (GCMS) implied that some new organic matters were produced in the effluent of SP-DBR due to biopolymer degradation and denitrification processes. The results could provide a new insight about the formation and stability of solid-phase denitrification PBS-biofilm via the point of microbial products.
\end{abstract}

\section{Introduction}

With the rapid development of global economy, nitrogen-containing wastewaters are increasingly produced from various industries and discharged into the environment (Cyplik et al., 2012). Till now, biological nitrification and denitrification process have been widely applied in wastewater treatment plant (WWTP) for nitrogen removal from municipal and industrial wastewaters. However, WWTP effluent may still contain a relatively high concentration of inorganic nitrogen such as nitrate and nitrite. It is well accepted that nitrate has a negative impact on the eutrophication of water environment as well as hazards to human health (Nuhogl et al., 2002; Robinsonlora and Brennan, 2009). Moreover, due to the increasingly strict wastewater discharge standard, advanced treatment of WWTP effluents is becoming an inevitable process for total nitrogen removal.

Recently, many methods have been applied to eliminate nitrate from WWTP effluent, including ion-exchange, reverse osmosis, electrodialysis and biological denitrification etc. Among all above methods, biological denitrification is generally applied to advanced wastewater treatment because of its advantages, such as high efficiency, cost-effective and environment-friendly (Foglar et al., 2005). In this process, organic carbon and nitrate are utilized as electron donor and acceptor by denitrifying bacteria, respectively. However, secondary effluent has limited carbon source for biological denitrification to achieve high removal efficiency of nitrate. To date, additional organic carbon source, such as ethanol, glucose, acetate, and methanol etc., is commonly applied to denitrification (Gómez et al., 2000). Nevertheless, the above soluble organic carbon sources can bring a lot of problems, such as complex operation, high-cost, and secondary pollution of effluent quality (Wu et al., 2013). In contrast, solid carbon source, also acting as biofilm carrier themselves, has been wildly exploited and developed for nitrate removal that could avoid the risks of overdosing or insufficient carbon dosing. Solid carbon sources are commonly divided into two types: synthetic polymers and natural materials (Wang and Wang, 2009). Compared with natural materials (e.g. wheat straw, cotton and waste newspaper), synthetic biodegradable polymers including Poly (butanediol succinate) (PBS), polyhydroxyalkanoates (PHAs), polycaprolactone (PCL), and poly-3-hydroxybutyric acid (PHB) as carbon sources could resolve color and excessive DOC problems in effluent (Boley et al., 2000; Zhu et al., 2015).

\footnotetext{
* Corresponding author.

E-mail address: dubin61@gmail.com (B. Du).
} 
Microbial products, i.e. extracellular polymeric substance (EPS) and soluble microbial product (SMP), are confirmed to have a significant influence on microbial activity of biologically based systems under dynamic conditions (NI and YU, 2012). As a wide range of complex organic compounds, EPS are located at or outside the cell surface, whereas SMP are the soluble cellular polymeric components dissolved in aqueous solution. Moreover, EPS are often described as dynamic double-layer-like structure, inner and outer, which composed of tightly bound EPS (TB-EPS) and loosely bound EPS (LB-EPS), respectively. It has been confirmed that EPS play an important role in mediating microbial adhesion onto bio-carrier surface and therefore maintain the mechanical stability of biofilm. In contrast, SMP are generally considered as one kind of organic compounds that are released from substrate microbial metabolism (usually with biomass growth and biomass decay) (Krasner et al., 2009; Laspidou and Rittmann, 2002). Since there are co-existed two processes in the solid-phase denitrification system, i.e. biopolymer degradation and denitrification, the production of both EPS and SMP may be more complex than the conventional denitrification process. Hence, it is essential to in-depth explore and identify the structure changes of two kinds of microbial products in order to better understand the formation and stability of solid-phase denitrification PBS-biofilm.

Therefore, the main objective of present study was to demonstrate the feasibility of solid-phase denitrification biofilm reactor (SP-DBR) achievement and long-term performance by using PBS as the carbon source and biofilm carrier for WWTP effluent treatment. To achieve this purpose, the changes of LB-EPS and TB-EPS were qualitatively and
quantitatively analyzed before and after PBS-biofilm formation by using

chemical and spectroscopic approaches. Meanwhile, a combination of excitation-emission matrix (EEM), Parallel factor analysis (PARAFAC), and Gas Chromatography-Mass Spectrometer (GC-MS) were applied to SMP production evaluation.

\section{Methods and materials}

\subsection{Experiment set-up}

The experiment was conducted in a perspex solid-phase denitrification biofilm reactor (SP-DBR) with the inner diameter and height of 12 and $25 \mathrm{~cm}$, respectively, which had a working volume of $3.4 \mathrm{~L}$ (schematic diagram was shown in Supplementary material). The SPDBR was filled with $40 \%$ PBS granules as solid carbon source and biofilm carrier for biological denitrification. The diameter and height of each PBS carrier were 3 and $5 \mathrm{~mm}$, respectively. Influent wastewater was stored in a water tank $(60 \mathrm{~L})$ and flowed into the reactor through a water pump. The volumetric exchange ratio of reactor was $50 \%$, and as a result, hydraulic retention time (HRT) was $24 \mathrm{~h}$.

Seed sludge was obtained from a lab-scale SBR, which has an effective volume of $18 \mathrm{~L}$ that running for over 1 year. The initial mixed liquor suspended solids (MLSS) concentration in SP-DBR was about $3.0 \mathrm{~g} / \mathrm{L}$. The SP-DBR was sequentially operated at a cycle of $720 \mathrm{~min}$, including 5 min influent $580 \mathrm{~min}$ anoxic phase, $10 \mathrm{~min}$ settling, $5 \mathrm{~min}$ effluent and 120 min idle. The system was automatically operated

through a time controller. The influent wastewater for SP-DBR was obtained from the effluent of the secondary tank after a lab-scale A/O reactor. The main compositions of the influent SP-DBR were as follows $(\mathrm{mg} / \mathrm{L}): \quad \mathrm{NH}_{4}^{+} \mathrm{eN}, \quad 3.5 \pm 1.1 ; \quad \mathrm{NO}_{2}^{-}{ }^{-} \mathrm{N}, \quad 2.0 \pm 0.3 ; \quad \mathrm{NO}_{3}^{-}{ }^{-} \mathrm{N}$, $25.9 \pm 1.7$ and COD, $30 \pm 2.0$.

\subsection{EPS, SMP extraction and fluorescent spectra}

Two types of EPS, including LB-EPS and TB-EPS, were extracted by using a heat method from seed sludge and biofilm as described previously literature (Yin et al., 2015). The supernatant was collected from reactor by centrifugation at $4000 \mathrm{rpm}$, and subsequently filtrated at $0.45-\mu \mathrm{m}$ membrane filter to represent SMP. 3D-EEM was obtained by subsequent scanning excitation from 200 to $400 \mathrm{~nm}$ at $10 \mathrm{~nm}$ increments, and the emission wavelength from 280 to $550 \mathrm{~nm}$ with a slitwidth of $10 \mathrm{~nm}$. Synchronous fluorescence spectra of SMP samples were determined by ranging the excitation wavelengths from 250 to $550 \mathrm{~nm}$ with offset $(\Delta \lambda)$ of $60 \mathrm{~nm}$. All samples were scanned at a speed of $1200 \mathrm{~nm} / \mathrm{min}$. PARAFAC decomposed $\mathrm{N}$-way arrays into $\mathrm{N}$ loading matrices was applied for the further analysis of SMP fluorescence data (Yu et al., 2010).

\subsection{Microbial community analysis}

Total genome DNA from two samples was extracted using CTAB/ SDS method. DNA concentration and purity was monitored on $1 \%$ agarose gels. According to the concentration, DNA was diluted to $1 \mathrm{ng} /$ $\mu \mathrm{L}$ using sterile water. A pair of universal $16 \mathrm{~S}$ rRNA gene primers, included 515F (GTGCCAGCMGCCGCGGTAA) and 806R (GGACTACHVGGGTWTCTAAT) were used to amplify V4 region of the 16S rRNA gene (Caporaso and Gordon, 2011). The reverse primer contained a 6-bp error-correcting barcode that was unique to each sample. The barcode was permuted for each sample and allowed the identification of individual samples in a mixture in a single Illumina MiSeq sequencing run. DNA was amplified in triplicate for each sample following the protocol described previously. The library quality was assessed on the Qubit@ 2.0 Fluorometer (Thermo Scientific) and Agilent Bioanalyzer 2100 system.

\subsection{Analytical methods}

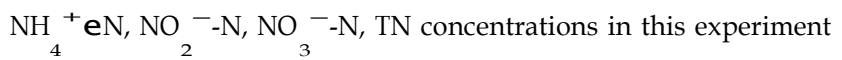
were determined according to their standard methods (Association and Washington, 1995). Polysaccharide content was determined by using anthrone-sulfuric acid method with glucose as the standard, and protein content was determined by using modified Lowry method with bovine serum albumin (BSA) as the standard. 3D-EEM spectra were characterized by using a Luminescence spectrometer (LS-55, Perkin-Elmer Co., USA). Types of organic composition of SMP sample was detected by using GC-MS (Shimadzu QP-2010). Fourier transform infrared spectroscopy (FTIR) analysis by using a Perkin-Elmer FTIR spectrometer (United States). Before FTIR analysis, EPS samples were freeze-dried at $-60{ }^{\circ} \mathrm{C}$.

\section{Results and discussion}

\subsection{Achievement and performance of $S P-D B R$}

After successive 180 days' operation, seed sludge was successfully attached onto the PBS surface and formed biofilm. Fig. 1 shows the long-term performance of nitrogen removal in the SP-DBR during the whole operation. It was found that the influent $\mathrm{NO}_{3}{ }^{-}-\mathrm{N}$ was average at $25.87 \pm 1.74 \mathrm{mg} / \mathrm{L}$, whereas $\mathrm{NH}_{4}{ }^{+} \mathrm{eN}$ and $\mathrm{NO}_{2}{ }^{-}{ }^{-} \mathrm{N}$ were $1.44 \pm 0.22$ and $0.25 \pm 0.21 \mathrm{mg} / \mathrm{L}$, respectively. As shown in Fig. $1 \mathrm{~A}-\mathrm{C}$, the $\mathrm{NO}_{3}{ }^{-}$$\mathrm{N}$ concentration in the effluent decreased to $1.22 \mathrm{mg} / \mathrm{L}$ and $\mathrm{NO}_{3}{ }^{-}-\mathrm{N}$ removal efficiency increased to $94.47 \%$ in start-up period (days $1-5)$,
while the effluent $\mathrm{NO}-\mathrm{N}$ and $\mathrm{NH}$-N remained at low levels (less while the effluent $\mathrm{NO}_{2}-\mathrm{N}$ and $\mathrm{NH}_{4}$ eN remained at low levels (less than $1.0 \mathrm{mg} / \mathrm{L}$ ). As the formation of PBS-biofilm, the nitrate removal efficiency further increased from $95.86 \pm 2.91 \%$ (days 6-44) to $97.34 \pm 1.23 \%$ (days $45-180$ ). This result may be attributed to small
craters and holes that developed by microbial corrosion, which provided greater adhesion area and anoxic environment for denitrification 

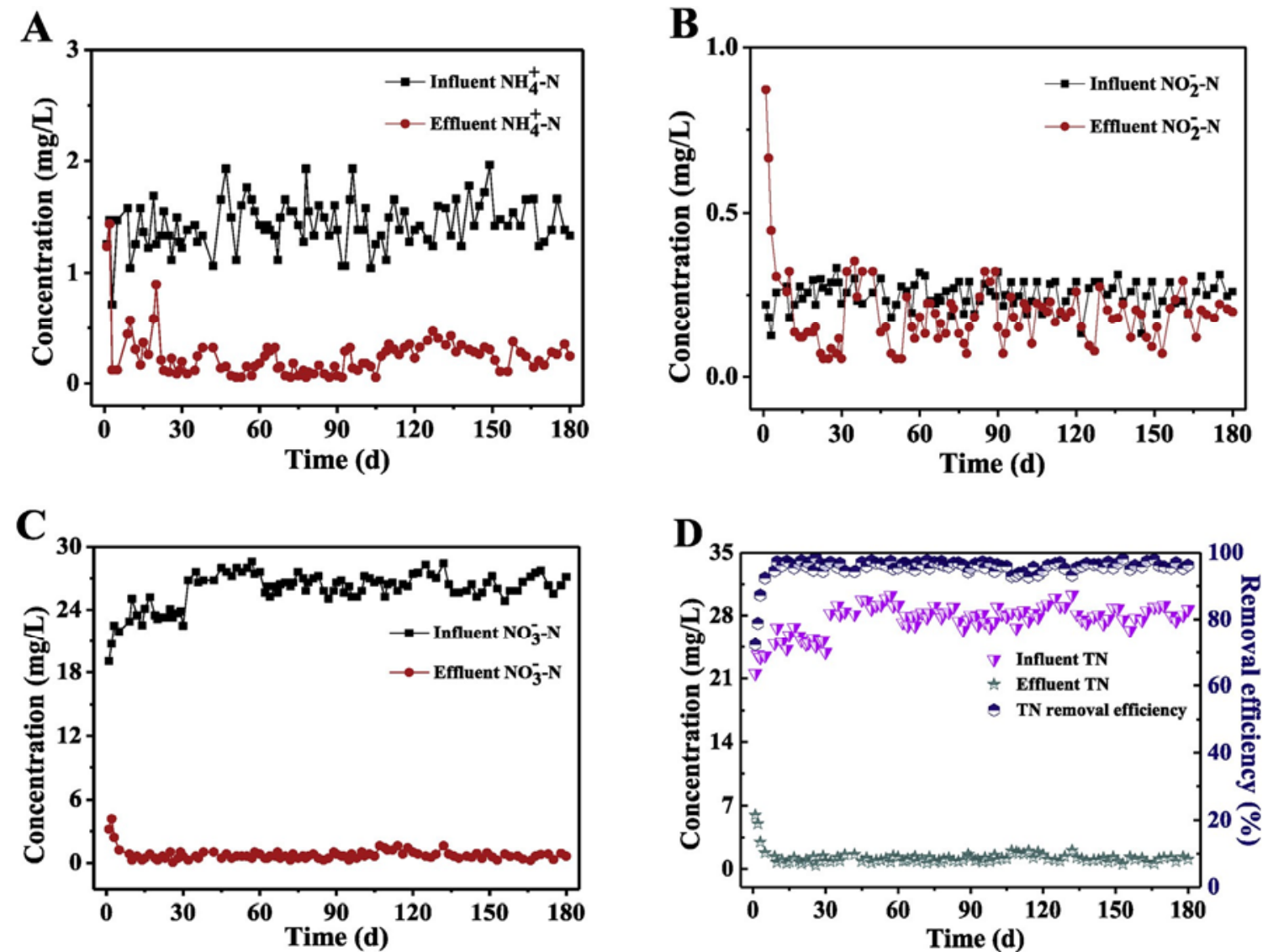

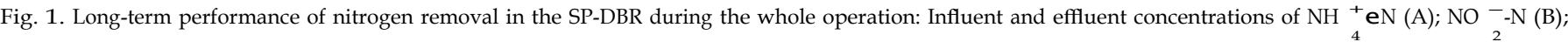
$\mathrm{NO}_{3}{ }^{-} \mathrm{N}(\mathrm{C})$ and $\mathrm{TN}$ removal efficiencies (D).

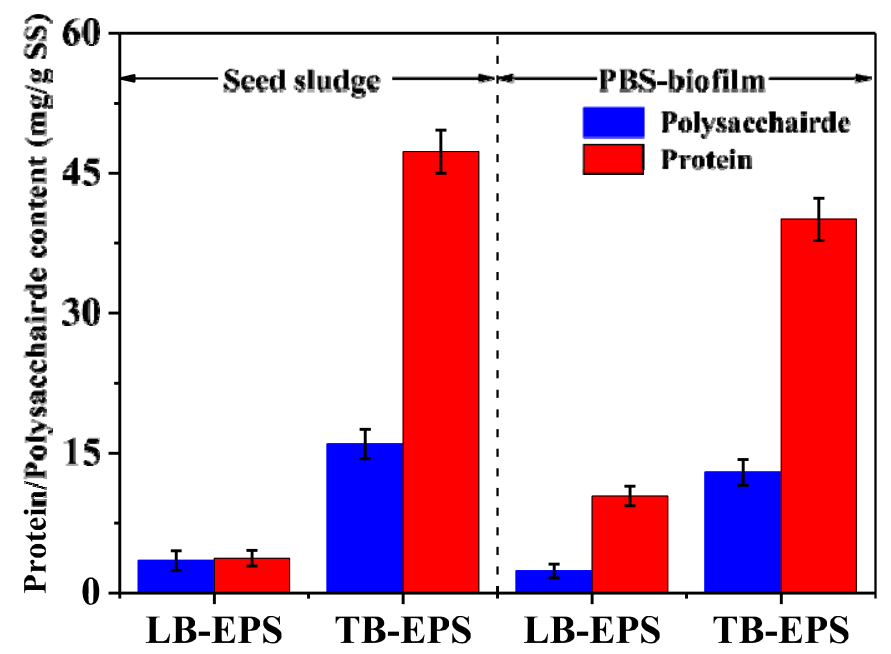

Fig. 2. The changed contents of LB-EPS and TB-EPS during the SP-DBR achievement process.

process, as similarly reported by Wu et al. (2013). Meanwhile, the TN removal efficiency was stabilized at approximately $96.38 \pm 1.1 \%$ (Fig. 1D).

The nitrogen transformation process in a typical cycle during stable operation phase was shown in Supplementary material. After the influent pumped into the reactor $(0-5 \mathrm{~min}), \mathrm{NO}_{3}{ }^{-}-\mathrm{N}$ concentration was rapidly reduced from 23.5 to $12.0 \mathrm{mg} / \mathrm{L}$ due to the dilution effect. Thereafter, $\mathrm{NO}_{3}{ }^{-} \mathrm{-}$ concentration decreased linearly from 11.2 to $0.6 \mathrm{mg} / \mathrm{L}$ with the final removal efficiency of $97.5 \%$ in the following eight hours. In contrast, $\mathrm{NO}_{2}{ }^{-}-\mathrm{N}$ concentration generally increased to the maximum peak of $2.6 \mathrm{mg} / \mathrm{L}$ at $7 \mathrm{~h}$, and subsequently decreased to $0.6 \mathrm{mg} / \mathrm{L}$ at $10 \mathrm{~h}$. Compared with acetate, methanol and glucose as carbon and electron sources, nitrite accumulation was much lower in solid-phase denitrification system (Ge et al., 2012). It is well reported that nitrite accumulation during denitrification process could be also affected by many parameters, such as carbon source species, carbon/ nitrogen $(\mathrm{C} / \mathrm{N})$ ratio, and $\mathrm{pH}$ value (Gómez et al., 2000; Glass and Silverstein, 1998).

In order to provide the evidence for PBS biodegradation and biofilm growth, SEM observations of PBS surface before and after utilization were conducted during 180 days' operation was shown in Supplementary material. It was found that the surface of raw PBS was relatively smooth, whereas it became rough with many hollows and holes caused by microbial corrosion. As a result, a large surface area and anoxic environment of PBS was provided for microorganism attachment and biological denitrification (Wu et al., 2013). Meanwhile, two different morphologies (rhabditiform and filament) of microorganism were observed in holes and hollows. Filamentous organisms played significant role on the connection between microorganism and PBS-surface that bring about the formation and stability of biofilm. SEM images also demonstrated that PBS was comparatively durable as carbon source for denitrification.

\subsection{Characteristic of EPS in biofilm formation}

Fig. 2 shows the contents of LB-EPS and TB-EPS from seed sludge and PBS-biofilm during the SP-DBR achievement process. It was observed that protein and polysaccharide contents in TB-EPS were much higher than those in LB-EPS, indicating that TB-EPS was the main distribution and constituent in the double-layered of EPS. Although LBEPS accounts for a small proportion in total EPS, it plays an important 
A

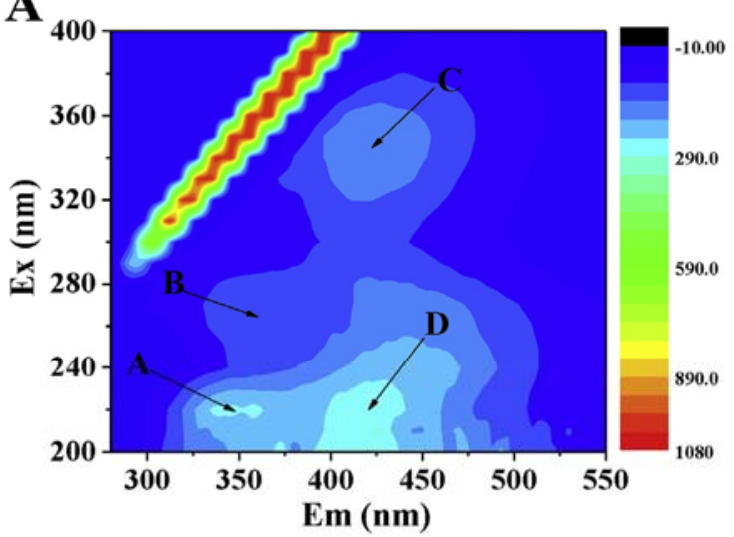

C

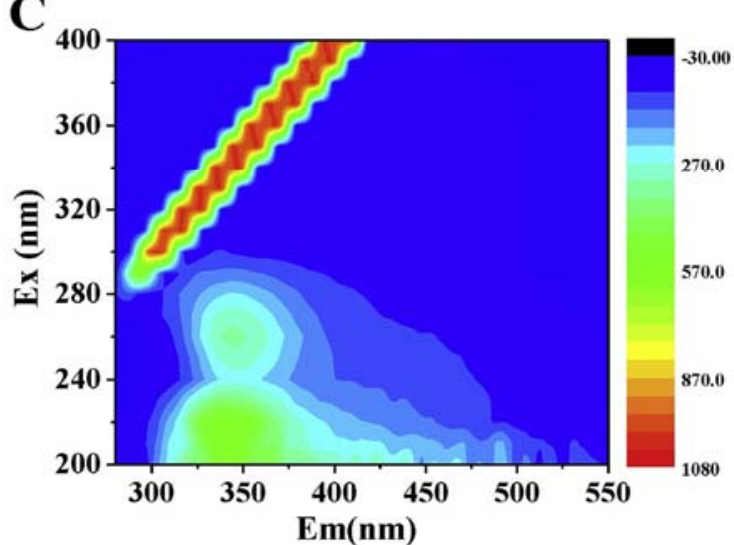

B

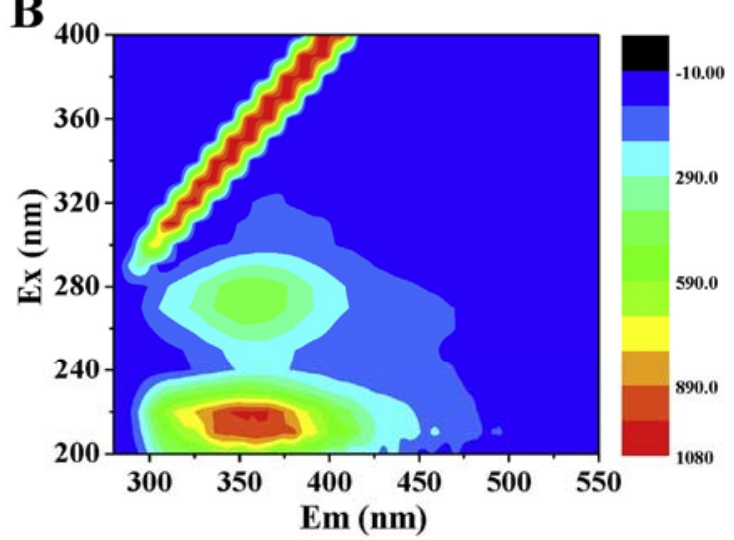

D

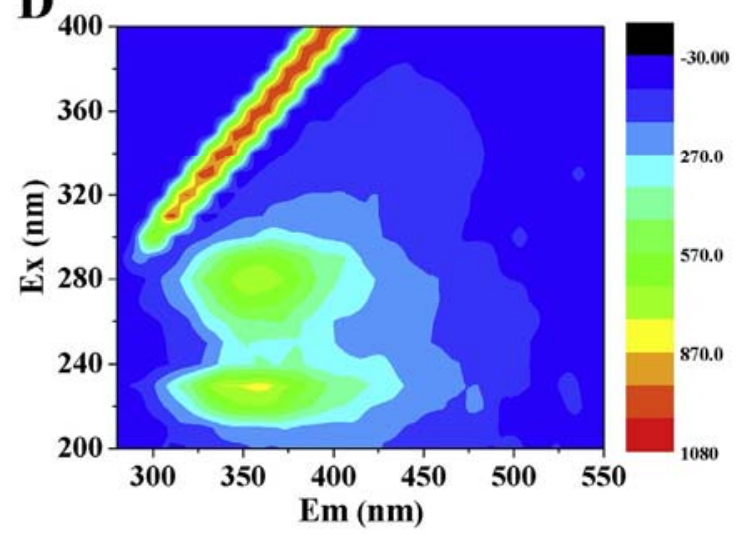

Fig. 3. Excitation emission matrix (EEM) spectra of LB-EPS and TB-EPS extracted from seed sludge and biofilm: (A) LB-EPS and (B) TB-EPS of seed sludge; (C) LB-EPS and (D) TB-EPS of biofilm.

role in the membrane fouling, sedimentation and flocculation etc. (Li and Yang, 2007; Wang et al., 2009). After the achievement of PBSbiofilm, protein and polysaccharide contents were reduced by $17.2 \%$ and $19.0 \%$ of TB-EPS, respectively (Fig. 2). It has been reported that protein and polysaccharide were represented as hydrophobic and hydrophilic substances in previous research, respectively (Bos et al., 1999). In present study, protein/polysaccharide ratio was lower in TBEPS of biofilm than that of seed sludge, suggesting that the relative hydrophobicity increased after the formation of PBS-biofilm, which may be attributed to high-MW and cross-linked structure of polysaccharides exhibited some influences on cell aggregation (Seviour et al., 2009).

Fig. 3 shows the EEM spectra of LB-EPS and TB-EPS extracted from seed sludge and biofilm. As shown in Fig. 3A, three main peaks (A, C and D) were identified in LB-EPS of seed sludge at excitation/emission wavelengths (Ex/Em) of 220/350, 340/420 and 225/430 nm, which were assigned to aromatic tryptophan protein-like substances, humiclike substances and fulvic acid-like substances, respectively (Meng et al., 2011). In contrast, only two peaks (Peak A and Peak B) were indentified at Ex/Em of 220/340 nm and 265-270/340-350 nm in LBEPS of biofilm (Fig. 3C), corresponding to the presence of aromatic and tryptophan protein-like substances. Peak A expressed higher fluorescent intensity in biofilm than that of seed sludge, suggesting that protein in LB-EPS was more sensitive to anoxic environment. It was found from Fig. 3B and D, two major peaks (aromatic protein-like and tryptophan protein-like substances) in TB-EPS were observed at Ex/Em wavelengths of 225-230/350-370 $\mathrm{nm}$ and 270-285/352.5-360 nm regardless of seed sludge or biofilm. For biofilm, there were only aromatic protein-like and tryptophan protein-like substances in two types of EPS, implying that protein-like substances played a significant role in the formation of PBS-biofilm. The significantly changed EPS composition may be in connection with the microorganisms by transferring from aerobic to anoxic environments, as similarly reported by Hong et al. (2007).

The FTIR spectra of LB-EPS and TB-EPS extracted from seed sludge and PBS-biofilm were shown in Supplementary material. It was observed that the position and number of FTIR peaks in two types of EPS of seed sludge and biofilm were no obvious difference, indicating that the types of chemical groups were similar. Specifically, the broad band around $3200-3600 \mathrm{~cm}^{-1}$ was related to the stretching vibration of both $\mathrm{O}-\mathrm{H}$ (of the polysaccharides) and amino groups (of the proteins) (Sun et al., 2009), which was more abundant in TB-EPS than that in LB-EPS regardless of seed sludge or PBS-biofilm. This result suggested that the TB-EPS had higher abundances of proteins and polysaccharides compared with LB-EPS (Basuvaraj et al., 2015). Meanwhile, TB-EPS of seed sludge exhibited higher peak intensities associated proteins than PBSbiofilm, which was in agreement with the chemical and fluorescent data. The band at approximately $1641-1651 \mathrm{~cm}^{-1}$ region was corresponded to the functional groups $C 】 \mathrm{C}$ stretching vibrations of aromatic proteins and $\mathrm{C} \mathbf{O}$ vibrations of amides, which existed in all of EPS samples and favored bio-flocculation (Badireddy et al., 2010). The bands near $1384-1429 \mathrm{~cm}^{-1}$ were related to symmetric stretching of eCOO- groups associated with amino acids and deprotonated carboxylic acid groups, which the indicated the acidic nature of EPS components (Badireddy et al., 2010). A sharp peak around $1112 \mathrm{~cm}^{-1}$ was correlated with the $\mathrm{C}-\mathrm{O}-\mathrm{C}$ and $\mathrm{C}-\mathrm{O}-\mathrm{H}$ stretching vibrations of polysaccharides and aromatics, indicating that polysaccharides were an important component of EPS (Wei et al., 2017). Some bands at "fingerprint zone" $\left(<1000 \mathrm{~cm}^{-1}\right)$ might be assigned to phosphate group, which was one of the functional groups of nucleic acids. Compared with 
LB-EPS, a new weak absorption band appeared at $2933-2964 \mathrm{~cm}^{-1}$ of TB-EPS, which were corresponding with the asymmetrical $\mathrm{C}-\mathrm{H}$ stretching vibration of the aliphatic $\mathrm{CH}_{2}$-group (Liang et al., 2010). Furthermore, the bands of LB-EPS at 3448, 1651 and $1384 \mathrm{~cm}^{-1}$ in seed sludge were shifted to 3411,1643 and $1411 \mathrm{~cm}^{-1}$ in biofilm, indicating that the chemical structure of EPS had changed after the formation of PBS-biofilm. FTIR data illustrated that EPS was a complex mixture, which was composed of proteins, polysaccharide, humic substances, amino acids and nucleic acids.

\subsection{Microbial community structure}

High-throughput sequencing analysis of $16 \mathrm{~S}$ rRNA amplicon technology was introduced to evaluate the variation and characteristics of microbial community during biofilm cultivation. Fig. 4A shows the different species of bacteria communities of seed sludge and biofilm at the phylum level. It was found that the vast majority of sequences in two sludge samples belonged to 10 phyla: Proteobacteria, Bacteroidetes, Firmicutes, Acidobacteria, Planctomycetes, Spirochaetes, Chloroflexi, Verrucomicrobia, Actinobacteria and Latescibacteria. There was a little difference of proportion in phylum of two samples. To be specific, the proportion of Proteobacteria, Firmicutes and Chloroflexi increased from $59.10 \%, 4.30 \%$ and $1.26 \%-70.83 \%, 6.04 \%$ and $1.80 \%$, while Bacteroidetes decreased from $9.35 \%$ to $5.18 \%$ with PBS-biofilm formation, indicating the microbial communities structure has changed caused by feed environment. Miura et al. (2007) reported that Chloroflexi was a special phylum responsible for SMP degradation such as carbohydrates and cellular materials. It is well known that the main function of anaerobic bacteria is destroy large molecules matter, such as proteins, cellulose and polysaccharides, which is an essential step for hydrolyzation and utilization of the solid carbon source.

As shown in Fig. 4B, the relative abundance of Betaproteobacteria and Flavobacteriia at the class level decreased from $47.40 \%$ to $3.9 \%$ $34.06 \%$ and $0.6 \%$, while Deltaproteobacteria, Gammaproteo- bacteria, Negativicutes observably increased from $2.27 \%, 5.11 \%$ and $0.13 \%-$ $16.31 \%, 10.09 \%$ and $4.51 \%$, respectively. In this study, within the Betaproteobacteria, Comamonadaceae and Rhodocyclaceae families became more abundant in biofilm sample (increased from $4.27 \%$ to $3.43 \%$ $17.94 \%$ and $10.24 \%$, data not shown). Hiraishi and Khan re- ported that most of polyhydroxyalkanoate-degrading denitrifying bac- teria have been proved belong to the family Comamonadaceae within Betaproteobacteria (Hiraishi and Khan, 2003). Miao et al. (2016) elaborated that Comamonadaceae was a dominating member participating in denitrification. Tang et al. (2017) reported that Rhodocyclaceae increased from $10.7 \%$ to $14.8 \%$ when fermentation liquid of food waste (FLFW) as an external carbon source added to anoxic/oxic-membrane bioreactor (A/O-MBR).

Fig. $4 \mathrm{C}$ shows the microbial community structure at genus levels with different sludge samples. The proportion of four genera, including Simplicispira, Dechloromonas, Diaphorobacter, Desulfovibrio, have an obvious increased with PBS-biofilm formation, which are identified to denitrifying bacteria. Khan et al. (2007) founded that most of the isolates $(90 \%)$ were assigned to genera of the Betaproteobacteria, especially those of the family Comamonadaceae (i.e., Acidovorax, Brachymonas, Comamonas, Diaphorobacter and Simplicispira). Meanwhile, Diaphorobacter was discovered that it possibly transfers electron sequentially in the denitrification system from nitrate to dinitrogen formationreported by Chakravarthy et al. (2011). Besides, Coates et al. (2001) reported that two Dechloromonas strains, RCB and JJ, can completely mineralize various mono-aromatic compounds with nitrate as the electron acceptor in the absence of $\mathrm{O}_{2}$. Moreover, small proportion of denitrifying bacteria was observed in genera level including Thauera, Pseudomonas, Denitromonas, which are the main functional microorganisms related with denitrification (Babatsouli et al., 2015).

\subsection{SMP production from SP-DBR system}

\subsubsection{Fluorescence spectra of SMP in a typical cycle}

EEM spectra has been successfully utilized to recognize the components of SMP owing to its particular advantages including strong selectivity, high sensitivity and easy operation (Yamashita and Jaffé, 2008). Fig. 5 shows 3D-EEM spectra of SMP samples in a typical cycle of SP-DBR (from 5 to $600 \mathrm{~min}$ ). It was observed that Peak A, C and D were identified at Ex/Em wavelengths of 280/350, 240-260/430-450 and $340 / 440 \mathrm{~nm}$, which were assigned to tryptophan protein-like substances, fulvic acid-like and humic-like substances, respectively (Sheng and $Y u, 2006)$. Peak B was firstly observed at Ex/Em of 230/350 nm at the $240 \mathrm{~min}$, which was regarded as aromatic protein-like substrates (Chan et al., 2009).

Generally, the release of SMP from solid-phase denitrification system was related the co-existed two processes: biopolymer degradation and denitrification. It was found that all above intensities of four fluorescence peaks expressed different trends with reaction time, implying that the species of SMP were changed in the influence of twocoexisted processes. The fluorescence intensity of Peak A increased from 248.95 to 391.60 a.u. at the first hour, which may be attributed to the increased microbial metabolism from denitrification process in the presence of solid substrate source (Thompson, 1976). At subsequent period, it was generally reduced to 142.77 a.u. till the end of cycle (600 $\mathrm{min})$, suggesting that the released protein-like substances may be gradually utilized as carbon source for denitrification process. Synchronous fluorescence results were consistent with 3D-EEM (detailed results in Supplementary material). Meanwhile, the intensity of Peak C had a slight change from 384.75 to 312.90 a.u., suggesting that fulvic acid-like substance were reduced through the denitrification process. The formation of SMP in solid-phase biological denitrification biofilm reactor was significant different with soluble organic carbon sources reported by Xie et al. (2010), who found that SMP concentration increased steadily as the utilization of external substrate (e.g. NaAC).

\subsubsection{PARAFAC analysis}

PARAFAC combined with 3D-EEM is utilized to decompose the fluorescence spectra into independent fluorescent phenomena (Bro, 1997). Fig. 6A shows the fluorescence components of SMP samples identified by PARAFAC based on EEM spectra. It was found that two Fluorescence components were derived from PARAFAC model. For component 1, two main peaks were observed at Ex/Em of 275/370 nm and $230 / 370 \mathrm{~nm}$, indicating the presence of tryptophan protein-like substances and aromatic protein-like substances, respectively. Component 2 also had two obvious peaks that occurring around Ex/Em of $350 / 440$ and $250 / 440 \mathrm{~nm}$, which were identified as humic-like and fulvic acid-like substances. Similar two kinds of components from PARAFAC have been also identified from SMP released from aerobic granular sludge under the stress of 2, 4-Dichlorophenol (Wei et al., 2016).

Fig. 6C shows the fluorescence intensity scores of two PARAFACderived components in SMP samples at different reaction time. It was found that the scores of two components expressed significant different trends during the denitrification process. The fluorescence intensity score of Component 1 increased from 0.40 to 0.42 in the initial $60 \mathrm{~min}$, suggesting the active microbial metabolism with utilization of solid substrate source for denitrification process under feast condition, 

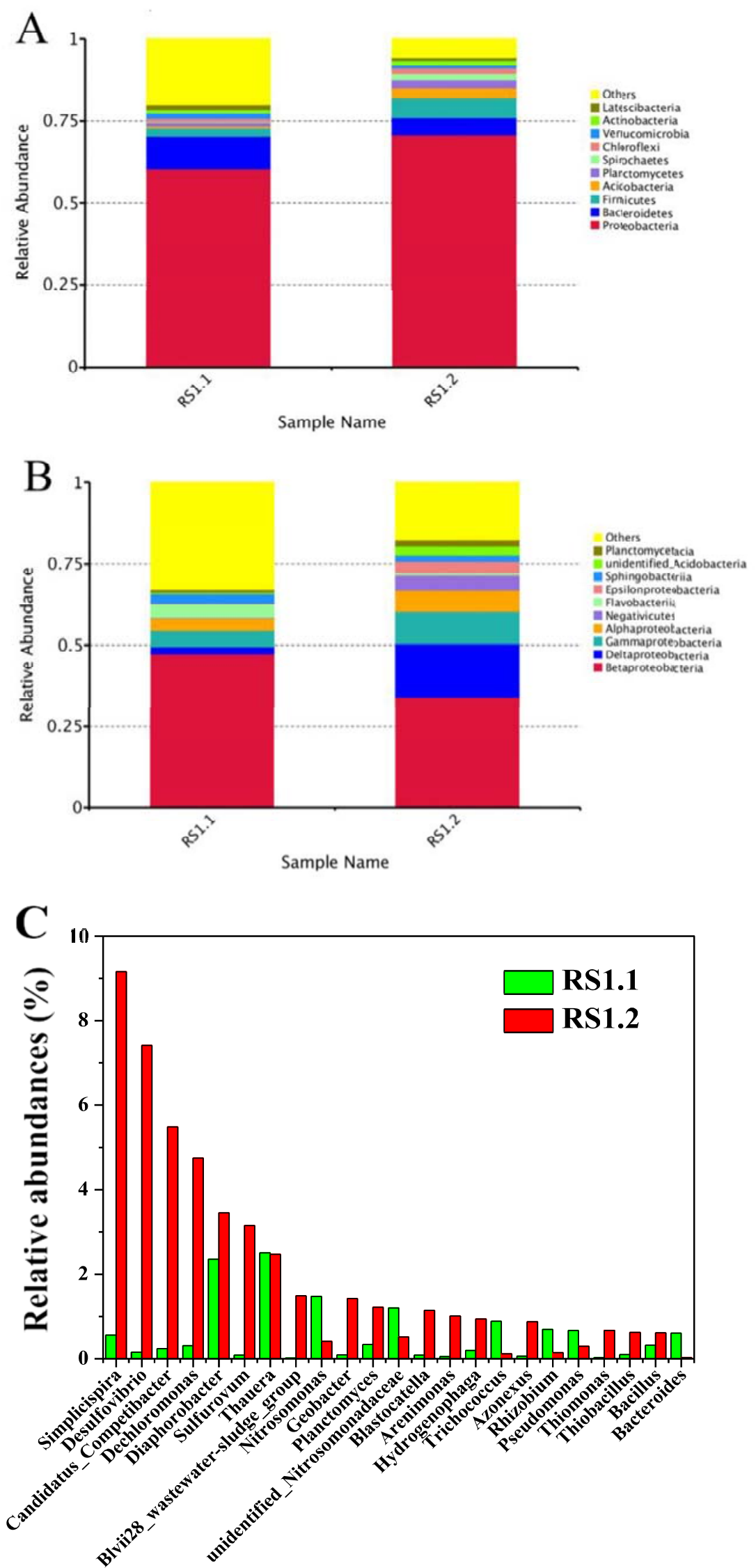

Fig. 4. Microbial community structure at phylum levels (A), class levels (B) and genus levels (C) of two sludge samples (Seed sludge sample, RS1.1; Biofilm sample, RS1.2). 

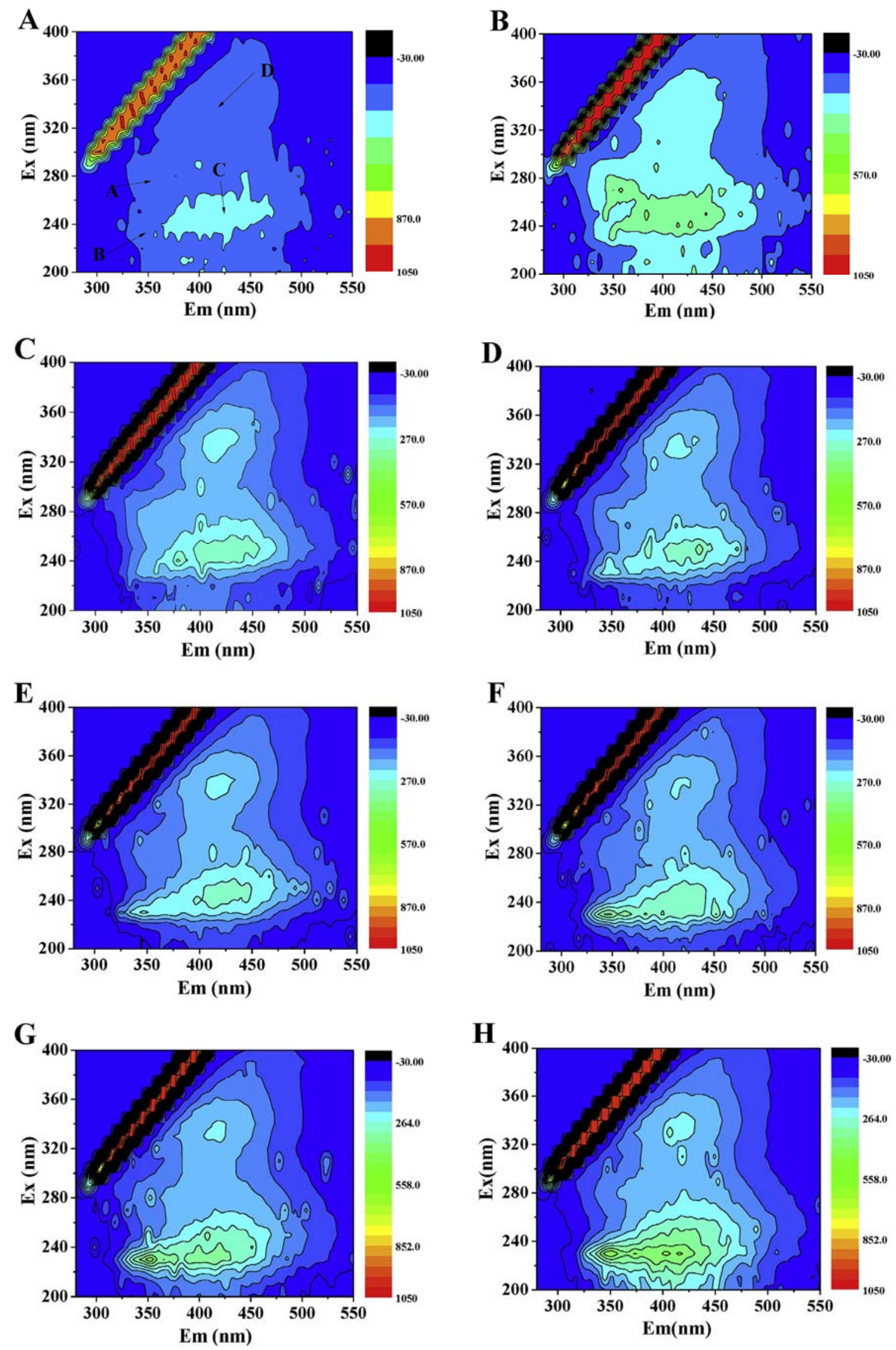

Fig. 5. Fluorescence spectra of SMP samples in a typical cycle of SP-DBR: (A) 5 min; (B) $60 \mathrm{~min}$; (C) $120 \mathrm{~min}$; (D) $240 \mathrm{~min}$; (E) $360 \mathrm{~min}$; (F) $480 \mathrm{~min}$; (G) $540 \mathrm{~min}$; (H) $600 \mathrm{~min}$. 

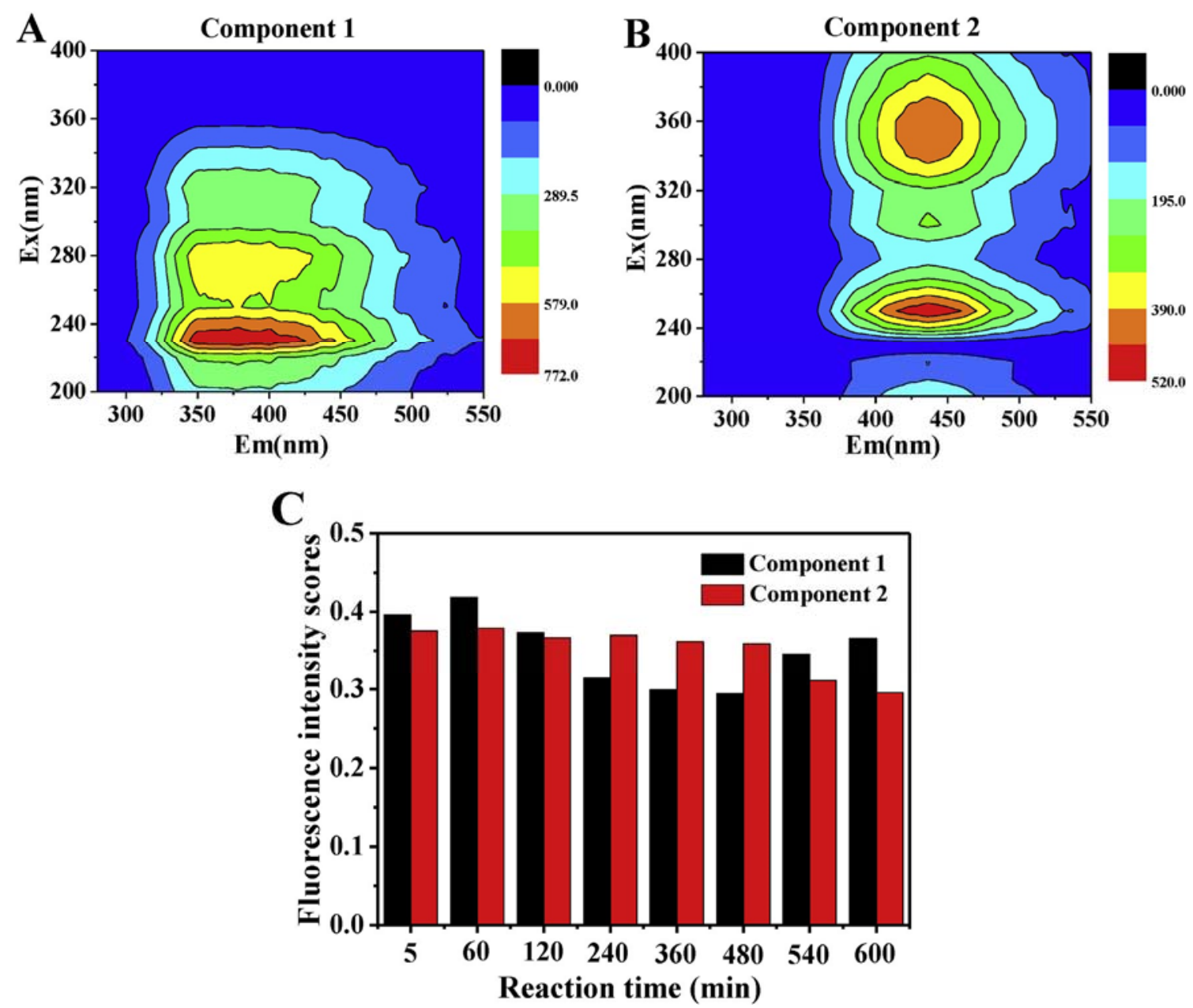

Fig. 6. Fluorescence components of SMP samples identified by PARAFAC based on EEM spectra: (A) Component 1; (B) Component 2; (C) Fluorescence intensity scores of two PARAFAC-derived components.

corresponding to previous literature reported by Yang et al. (2017). Afterwards, the score of Component 1 was generally reduced to 0.29 at $480 \mathrm{~min}$, implying that the released protein-like substances may be utilized as carbon source for denitrification process. After the substrate was completely consumed, the increase in SMP concentration may because the SMP produced from microbial decay (Xie et al., 2010). Correspondingly, the fluorescence intensity score in Component 2 was reduced from 0.38 at $5 \mathrm{~min}$ to 0.30 at $600 \mathrm{~min}$. Moreover, it was well reported that the humic-like substances were mainly substrate-utilization associated, while the fulvic acid-like substances were non growthassociated (Ni et al., 2010).

\subsubsection{GC-MS analysis}

GC-MS method was further applied as qualitative and quantitative analysis the type of main organic matters in the influent and effluent of SP-DBR (Bai et al., 2017). As shown in Table 1, there were about 16 classes organic matters identified from influent of SP-DBR, including alcohols, ketones, esters, and alkanes etc. The $\mathrm{N}$-containing compounds was mainly constituted by pyridine, 2-methyl and pyrrole molecules, which may be attributed to proteins in the organic fraction of wastewater (Gonzalez-Vila et al., 2009). After solid-phase biological denitrification, the number of the main organic species decreased to 7 (Table 2). It can be seen that some organic matters, such as Succindialdehyde, 1, 3-Propanediol, 2, 1-Benzisoxazole was not detected in the effluent. Moreover, some new organic substances, such as 1,2Benzenedicarboxylic acid dibutyl ester, 1,3-Benzodioxol-2-one, which were related with aromatic and poly-aromatic substances (Pognani et al., 2011). This result may be due to the decomposition of quondam organic matters by microbial activities in biological denitrification and biopolymer degradation processes. In previous studies, Pognani et al. (2011) reported that 16 classes organic matters identified in a full-scale composting for treatment sewage sludge and biowaste, which including fatty acids, cycle-alkanes, alkanes, cycle-alkenes, alkenes, alcohols, ketones, aldehydes, halogens, nitrogen compounds and aromatic molecules etc. Dignac et al. (2005) investigated that fatty acids were abundant composition of organic matter in various fresh and composted wastes.

\section{Conclusions}

In summary, WWTP effluent was successfully treated in a SP-DBR by using PBS as carbon source and biocarrier. High $\mathrm{NO}_{3}{ }^{-}-\mathrm{N}$ and TN removal efficiencies achieved during stable operation phase. The contents and compositions of both LB-EPS and TB-EPS were significant changed after PBS-biofilm formation. Microbial analysis suggested that Comamonadaceae and Rhodocyclaceae within the Betaproteobacteria were dominant families. Two components were identified from SMP in PBS-biofilm system, including protein-like substances for Component 1 , humic-like and fulvic acid-like substances for Component 2. Moreover, the number of organic matter species in two SMPs were detected by GCMS reduced from 16 to 7 . 
Table 1

Main organic matters in the influent of DBR detected by GC-MS.

\begin{tabular}{|c|c|c|c|}
\hline Full name & Chemical formula & \#CAS & Chemical structure \\
\hline Cyclohexanone & $\mathrm{C}_{6} \mathrm{H}_{10} \mathrm{O}$ & $108-94-1$ & \\
\hline Succindialdehyde & $\mathrm{C}_{4} \mathrm{H}_{6} \mathrm{O}_{2}$ & $638-37-9$ & \\
\hline 1,3-Propanediol & $\mathrm{C}_{3} \mathrm{H}_{8} \mathrm{O}_{2}$ & 504-63-2 & \\
\hline 4-Pyridinamine, $\mathrm{N}, \mathrm{N}, 2$-trimethyl- & $\mathrm{C}_{8} \mathrm{H}_{12} \mathrm{~N}_{2}$ & $37941-24-5$ & \\
\hline 2,3,5-Trimethyl-4-methylene-2-cyclopenten-1-one & $\mathrm{C}_{9} \mathrm{H}_{12} \mathrm{O}$ & 29765-85-3 & \\
\hline Imidazo[1,5-a]pyrimidine & $\mathrm{C}_{6} \mathrm{H}_{5} \mathrm{~N}_{3}$ & 274-67-9 & \\
\hline 2,1-Benzisoxazole & $\mathrm{C}_{7} \mathrm{H}_{5} \mathrm{NO}$ & 271-58-9 & \\
\hline Naphthalene & $\mathrm{C}_{10} \mathrm{H}_{8}$ & $91-20-3$ & \\
\hline Tert-Butyl N-Hydroxycarbamate & $\mathrm{C}_{5} \mathrm{H}_{11} \mathrm{NO}_{3}$ & 36016-38-3 & \\
\hline Pentanal dipropyl acetal & $\mathrm{C}_{11} \mathrm{H}_{24} \mathrm{O}_{2}$ & $13112-64-6$ & $\mathrm{H}$ \\
\hline 2-Methyl naphthalene & $\mathrm{C}_{11} \mathrm{H}_{10}$ & $91-57-6$ & \\
\hline 4-Pentenoic acid & $\mathrm{C}_{5} \mathrm{H}_{8} \mathrm{O}_{2}$ & $591-80-0$ & \\
\hline (Dimethylcyclohexyl) hydrogen phthalate & $\mathrm{C}_{16} \mathrm{H}_{20} \mathrm{O}_{4}$ & 1322-94-7 & \\
\hline 1,4-Benzenedicarboxylic acid 1,4-dibutyl ester & $\mathrm{C}_{16} \mathrm{H}_{22} \mathrm{O}_{4}$ & 1962-75-0 & \\
\hline Toluene,3,4-bis(benzyloxy)-a-chloro-(7Cl) & $\mathrm{C}_{21} \mathrm{H}_{19} \mathrm{ClO}_{2}$ & 1699-59-8 & \\
\hline 9-Octadecenamide & $\mathrm{C}_{18} \mathrm{H}_{35} \mathrm{NO}$ & $3322-62-1$ & \\
\hline
\end{tabular}


Table 2

Main organic matters in the effluent of DBR detected by GC-MS.

\begin{tabular}{|c|c|c|c|}
\hline Full name & Chemical formula & \#CAS & Chemical structure \\
\hline Cyclohexanone & $\mathrm{C}_{6} \mathrm{H}_{10} \mathrm{O}$ & $108-94-1$ & \\
\hline Naphthalene & $\mathrm{C}_{10} \mathrm{H}_{8}$ & $91-20-3$ & \\
\hline 2-Methyl naphthalene & $\mathrm{C}_{11} \mathrm{H}_{10}$ & $91-57-6$ & \\
\hline 7H-Benzocycloheptene & $\mathrm{C}_{11} \mathrm{H}_{10}$ & $264-09-5$ & \\
\hline 1,2-Benzenedicarboxylic acid dibutyl ester & $\mathrm{C}_{16} \mathrm{H}_{22} \mathrm{O}_{4}$ & $84-74-2$ & \\
\hline 1,3-Benzodioxol-2-one & $\mathrm{C}_{7} \mathrm{H}_{4} \mathrm{O}_{3}$ & $2171-74-6$ & \\
\hline Erucylamide & $\mathrm{C}_{22} \mathrm{H}_{43} \mathrm{NO}$ & $112-84-5$ & \\
\hline
\end{tabular}

\section{Acknowledgments}

This study was supported by the National Natural Science Foundation of China (21777056, 51508226), the Key Research and Development project of Shandong Province (2018GSF117027), and QW thanks the Special Foundation for Taishan Scholar Professorship of Shandong Province and UJN (No. ts20130937).

\section{Appendix A. Supplementary data}

Supplementary data related to this article can be found at https:/ / doi.org/10.1016/j.jenvman.2018.09.002.

\section{References}

Association, C., Washington, D., 1995. APHA, A. P. H. A. : standard methods for the examination of water and wastewater. Am. Phys. Edu. Rev. 24, 481-486.

Babatsouli, P., Fodelianakis, S., Paranychianakis, N., Venieri, D., Dialynas, M. Kalogerakis, N., 2015. Single stage treatment of saline wastewater with marine bacterial-microalgae consortia in a fixed-bed photobioreactor. J. Hazard. Mater. 292, 155.

Badireddy, A.R., Chellam, S., Gassman, P.L., Engelhard, M.H., Lea, A.S., Rosso, K.M., 2010. Role of extracellular polymeric substances in bioflocculation of activated sludge microorganisms under glucose-controlled conditions. Water Res. 44, 45054516.

Bai, Z., Wang, J., Yang, Q., 2017. Advanced treatment of municipal secondary effluent by catalytic ozonation using Fe3O4-CeO2/MWCNTs as efficient catalyst. Environ. Sci. Pollut. Res. 1-13.

Basuvaraj, M., Fein, J., Liss, S.N., 2015. Protein and polysaccharide content of tightly and loosely bound extracellular polymeric substances and the development of a granular activated sludge floc. Water Res. 82, 104-117.

Boley, A., Müller, W.R., Haider, G., Piedrahita, R.H., Verreth, J., 2000. Biodegradable polymers as solid substrate and biofilm Carrier for denitrification in recirculated aquaculture systems. Aquacult. Eng. 22, 75-85.

Bos, R., Hc, V.D.M., Busscher, H.J., 1999. Physico-chemistry of initial microbial adhesive interactions-its mechanisms and methods for study. FEMS Microbiol. Rev. 23, 179. Bro, R., 1997. PARAFAC. Tutorial and applications. Chemometr. Intell. Lab. Syst. 38 149-171.

Caporaso, J.G., Gordon, J.I., 2011. Global patterns of 16s rrna diversity at a depth of millions of sequences per sample. Proc. Natl. Acad. Sci. U. S. A. 108 (Suppl. 1), 4516.

Chakravarthy, S.S., Pande, S., Kapoor, A., Nerurkar, A.S., 2011. Comparison of denitrification between Paracoccus sp. and Diaphorobacter sp. Appl. Biochem. Biotechnol. $165,260$.

Chan, Y.J., Chong, M.F., Chunglim, L., Hassell, D.G., 2009. A review on anaerobic-aerobic treatment of industrial and municipal wastewater. Chem. Eng. J. 155, 1-18.

Coates, J.D., Chakraborty, R., Lack, J.G., O'Connor, S.M., Cole, K.A., Bender, K.S., Achenbach, L.A., 2001. Anaerobic benzene oxidation coupled to nitrate reduction in pure culture by two strains of Dechloromonas. Nature 411, 1039-1043.

Cyplik, P., Marecik, R., Piotrowska-Cyplik, A., Olejnik, A., Drożdżyńska, A., Chrzanowski, Ł., 2012. Biological denitrification of high nitrate processing wastewaters from explosives production plant. Water, Air, Soil Pollut. 223, 1791.

Dignac, M.F., Houot, S., Francou, C., Derenne, S., 2005. Pyrolytic study of compost and waste organic matter. Org. Geochem. 36, 1054-1071.

Foglar, L., Briski, F., Sipos, L., Vuković, M., 2005. High nitrate removal from synthetic wastewater with the mixed bacterial culture. Bioresour. Technol. 96, 879-888.

Gómez, M.A., Gonzálezlópez, J., Hontoriagarcía, E., 2000. Influence of carbon source on nitrate removal of contaminated groundwater in a denitrifying submerged filter. J. Hazard. Mater. 80, 69-80.

Ge, S., Peng, Y., Wang, S., Lu, C., Cao, X., Zhu, Y., 2012. Nitrite accumulation under constant temperature in anoxic denitrification process: the effects of carbon sources and COD/NO 3-N. Bioresour. Technol. 114, 137-143.

Glass, C., Silverstein, J.A., 1998. Denitrification kinetics of high nitrate concentration water: $\mathrm{pH}$ effect on inhibition and nitrite accumulation. Water Res. 32, 831-839.

Gonzalez-Vila, F., Gonzalez-Perez, J., Akdi, K., Gomis, M., Perez-Barrera, F., Verdejo, T., 2009. Assessing the efficiency of urban waste biocomposting by analytical pyrolysis (Py-GC/MS). Bioresour. Technol. 100, 1304-1309.

Hiraishi, A., Khan, S.T., 2003. Application of polyhydroxyalkanoates for denitrification in water and wastewater treatment. Appl. Microbiol. Biotechnol. 61, 103-109.

Hong, S.H., Lee, W.N., Oh, H.S., Yeon, K.M., Hwang, B.K., Lee, C.H., Chang, I.S., Lee, S., 2007. The effects of intermittent aeration on the characteristics of bio-cake layers in a membrane bioreactor. Environ. Sci. Technol. 41, 6270-6276.

Khan, S.T., Horiba, Y., Takahashi, N., Hiraishi, A., 2007. Activity and community composition of denitrifying bacteria in poly(3-hydroxybutyrate-co-3-hydroxyvalerate)using solid-phase denitrification processes. Microb. Environ. 22, 20-31.

Krasner, S.W., Westerhoff, P., Chen, B., Rittmann, B.E., Nam, S.-N., Amy, G., 2009. Impact 
of wastewater treatment processes on organic carbon, organic nitrogen, and DBP precursors in effluent organic matter. Environ. Sci. Technol. 43, 2911-2918.

Laspidou, C.S., Rittmann, B.E., 2002. A unified theory for extracellular polymeric substances, soluble microbial products, and active and inert biomass. Water Res. 36, 2711-2720.

Li, X.Y., Yang, S.F., 2007. Influence of loosely bound extracellular polymeric substance (EPS) on the flocculation, sedimentation and dewaterability of activated sludge. Water Res. 41, 1022-1030.

Liang, Z.W., Li, W.H., Yang, S.Y., Ping, D., 2010. Extraction and structural characteristics of extracellular polymeric substances (EPS), pellets in autotrophic nitrifying biofilm and activated sludge. Chemosphere 81,626 .

Meng, F., Zhou, Z., Ni, B.J., Zheng, X., Huang, G., Jia, X., Li, S., Xiong, Y., Kraume, M., 2011. Characterization of the size-fractionated biomacromolecules: tracking their role and fate in a membrane bioreactor. Water Res. 45, 4661-4671.

Miao, L., Wang, S., Li, B., Cao, T., Zhang, F., Wang, Z., Peng, Y., 2016. Effect of carbon source type on intracellular stored polymers during endogenous denitritation (ED) treating landfill leachate. Water Res. 100, 405-412.

Miura, Y., Watanabe, Y., Okabe, S., 2007. Significance of Chloroflexi in performance of submerged membrane bioreactors (MBR) treating municipal wastewater. Environ. Sci. Technol. 41,7787.

Ni, B.-J., Zeng, R.J., Fang, F., Xie, W.-M., Sheng, G.-P., Yu, H.-Q., 2010. Fractionating soluble microbial products in the activated sludge process. Water Res. 44, 22922302.

NI, B., YU, H., 2012. Microbial products of activated sludge in biological wastewater treatment systems: a critical review. Crit. Rev. Environ. Sci. Technol. 42, 187-223.

Nuhogl, A., Pekdemir, T., Yildiz, E., Keskinler, B., Akay, G., 2002. Drinking water denitrification by a membrane bio-reactor. Water Res. 36, 1155-1166.

Pognani, M., Barrena, R., Font, X., Adani, F., Scaglia, B., Sánchez, A., 2011. Evolution of organic matter in a full-scale composting plant for the treatment of sewage sludge and biowaste by respiration techniques and pyrolysis-GC/MS. Bioresour. Technol. $102,4536-4543$.

Robinsonlora, M.A., Brennan, R.A., 2009. The use of crab-shell chitin for biological denitrification: batch and column tests. Bioresour. Technol. 100, 534

Seviour, T., Pijuan, M., Nicholson, T., Keller, J., Yuan, Z., 2009. Gel-forming exopolysaccharides explain basic differences between structures of aerobic sludge granules and floccular sludges. Water Res. 43, 4469-4478.

Sheng, G.P., Yu, H.Q., 2006. Characterization of extracellular polymeric substances of aerobic and anaerobic sludge using three-dimensional excitation and emission matrix fluorescence spectroscopy. Water Res. 40, 1233-1239.

Sun, X.F., Wang, S.G., Zhang, X.M., Chen, J.P., Li, X.M., Gao, B.Y., Ma, Y., 2009.
Spectroscopic study of $\mathrm{Zn}^{2+}$ and $\mathrm{Co}^{2+}$ binding to extracellular polymeric substances (EPS) from aerobic granules. J. Colloid Interface Sci. 335, 11-17.

Tang, J., Wang, X.C., Hu, Y., Ngo, H.H., Li, Y., Zhang, Y., 2017. Applying fermentation liquid of food waste as carbon source to a pilot-scale anoxic/oxic-membrane bioreactor for enhancing nitrogen removal: microbial communities and membrane fouling behaviour. Bioresour. Technol. 236, 164.

Thompson, J., 1976. Characteristics and energy requirements of an alpha-aminoisobutyric acid transport system in Streptococcus lactis. J. Bacteriol. 127, 719.

Wang, X.M., Wang, J.L., 2009. Removal of nitrate from groundwater by heterotrophic denitrification using the solid carbon source. Sci. China Chem. 52, 236-240.

Wang, Z., Wu, Z., Tang, S., 2009. Extracellular polymeric substances (EPS) properties and their effects on membrane fouling in a submerged membrane bioreactor. Water Res. 43, 2504-2512

Wei, D., Dong, H., Wu, N., Ngo, H.H., Guo, W., Du, B., Wei, Q., 2016. A fluorescence approach to assess the production of soluble microbial products from aerobic granular sludge under the stress of 2,4-Dichlorophenol. Sci. Rep. 6, 24444.

Wei, D., Yan, T., Zhang, K., Chen, Y., Wu, N., Du, B., Wei, Q., 2017. Qualitative and quantitative analysis of extracellular polymeric substances in partial nitrification and full nitrification reactors. Bioresour. Technol. 240, 171-176.

Wu, W., Yang, L., Wang, J., 2013. Denitrification using PBS as carbon source and biofilm support in a packed-bed bioreactor. Environ. Sci. Pollut. Control Ser. 20, 333-339.

Xie, W.-M., Ni, B.-J., Zeng, R.J., Sheng, G.-P., Yu, H.-Q., Song, J., Le, D.-Z., Bi, X.-J., Liu, C.-Q., Yang, M., 2010. Formation of soluble microbial products by activated sludge under anoxic conditions. Appl. Microbiol. Biotechnol. 87, 373-382.

Yamashita, Y. Jaffé, R., 2008. Characterizing the interactions between trace metals and dissolved organic matter using excitation-emission matrix and parallel factor analysis. Environ. Sci. Technol. 42, 7374-7379.

Yang, J., Zhang, X., Sun, Y., Li, A., Ma, F., 2017. Formation of Soluble Microbial Products and Their Contribution as Electron Donors for Denitrification.

Yin, C., Meng, F., Chen, G.H., 2015. Spectroscopic characterization of extracellular polymeric substances from a mixed culture dominated by ammonia-oxidizing bacteria. Water Res. 68, 740-749.

Yu, G.H., Luo, Y.H., Wu, M.J., Tang, Z., Liu, D.Y., Yang, X.M., Shen, Q.R., 2010. PARAFAC modeling of fluorescence excitation-emission spectra for rapid assessment of compost maturity. Bioresour. Technol. 101, 8244-8251.

Zhu, S.M., Deng, Y.L., Ruan, Y.J., Guo, X.S., Shi, M.M., Shen, J.Z., 2015. Biological denitrification using poly(butylene succinate) as carbon source and biofilm Carrier for recirculating aquaculture system effluent treatment. Bioresour. Technol. 192, 603610 